\title{
Tecido Adiposo Epicárdico: Um Novo Parâmetro de Imagem Cardiovascular Profundamente Relacionado às Doenças Cardiovasculares
}

\author{
Epicardial Adipose Tissue: A New Cardiovascular Imaging Parameter Deeply Connected with \\ Cardiovascular Diseases
}

Eduardo Thadeu de Oliveira Correia ${ }^{\circledR}$ e Letícia Mara dos Santos Barbetta ${ }^{1}$

Hospital Universitário Antônio Pedro, ${ }^{1}$ Niterói, RJ - Brasil

\section{Prezado Editor,}

Lemos com grande interesse o artigo intitulado "A relação entre o tecido adiposo epicárdico e a resistência à insulina em crianças obesas" ${ }^{1}$ Nesse artigo, os autores realizaram ecocardiografia doppler tecidual para avaliar a espessura do tecido adiposo epicárdico (TAE), retardo eletromecânico (REM) e outras medições padrão em 94 pacientes pediátricos obesos. ${ }^{1}$ Pacientes com Avaliação do Modelo Homeostático para Resistência à Insulina (HOMA-IR) maior que o percentil 90 em uma curva de percentil específica para idade e sexo foram rotulados como tendo resistência à insulina $(\mathrm{RI}) .{ }^{1} \mathrm{O}$ estudo apontou que o grupo com RI tinha espessura significativamente maior de TAE do que os pacientes incluídos sem RI $(7,15$ vs. 5,5 mm, $p<0,004$, respectivamente) e REM inter e intra-atrial prolongado no grupo IR em comparação com o grupo não IR ( $p<0,010 ; p=0,032$, respectivamente). ${ }^{1}$ Além disso, os autores verificaram que um valor de corte para TAE de $>3,85 \mathrm{~mm}$ poderia predizer RI com 92,5\% de especificidade e $68,5 \%$ de sensibilidade $(p=0,002) .{ }^{1}$ $\mathrm{O}$ estudo concluiu que o TAE poderia ser usado para identificar RI em crianças, pois afirma-se que o TAE é parâmetro barato e acessível que pode ser facilmente medido com ecocardiografia. ${ }^{1}$

Em relação ao REM, associado ao desenvolvimento de fibrilação atrial (FA), ${ }^{1}$ seria interessante realizar uma análise multivariada para determinar se a espessura do TAE está independentemente associada ao REM. O TAE é um depósito de gordura visceral localizado ao redor do miocárdio e do pericárdio, secretando diversas quimiocinas e citocinas pró-inflamatórias, coletivamente denominadas de adipocinas. ${ }^{2}$ Devido à proximidade do TAE com o miocárdio, a gordura epicárdica pode promover efeitos locais inflamatórios e mecânicos no músculo cardíaco e nos vasos coronarianos. O TAE também exerce um papel cardioprotetor no coração, prevenindo os efeitos tóxicos dos ácidos graxos livres de alta circulação no miocárdio e nas artérias coronárias, reduzindo a tensão vascular e prevenindo a remodelação vascular. ${ }^{2}$ Estudos anteriores também observaram uma associação independente entre TAE e doenças cardiovasculares como a doença arterial coronariana, insuficiência cardíaca e FA. ${ }^{2}$ Uma metanálise de Gaeta et al., ${ }^{3}$ mostrou uma associação entre TAE e FA. ${ }^{3}$ Portanto, o TAE poderia ter um papel na gênese da arritmia, pois poderia ser um modulador, substrato ou gatilho no desenvolvimento de $\mathrm{FA}^{3}$ e seria interessante investigar sua associação com o REM.

No entanto, embora os achados desse estudo ${ }^{1}$ tenham sido interessantes, devemos levar em consideração a sensibilidade consideravelmente baixa da mensuração do TAE para identificar RI em pacientes pediátricos obesos $(68,5 \%)$. Os testes de triagem devem ter alta sensibilidade para minimizar os riscos de falsos negativos. Além disso, embora a ecocardiografia possa ser mais barata do que certos exames laboratoriais em alguns países, como o Brasil, a ecocardiografia é mais cara na maioria dos países por ter alto custo de mão de obra humana associado. Além disso, o TAE não costuma ser medido em laboratórios de ecocardiografia, nem a ecocardiografia é o método padrão ouro para medir o TAE, conforme citado pelos autores.

\section{Palavras-chave}

Pericárdio; Tecido Adiposo; Obesidade; Criança; Resistência à Insulina; Ecocardiografia/métodos.

Correspondência: Eduardo Thadeu de Oliveira Correia •

Avenida Marquês do Paraná, 303. CEP 24033-900, Centro, Niterói, RJ - Brasil

E-mail: etocorreia@outlook.com

Artigo recebido em 11/04/2020, revisado em 21/05/2020, aceito em 21/05/2020

DOI: https://doi.org/10.36660/abc.20200309 


\section{Carta ao Editor}

\section{Referências}

1. Güneş H, Güneş H, Temiz F. The Relationship Between Epicardial Adipose Tissue and Insulin Resistance in Obese Children. Arq Bras Cardiol. 2020 Mar 13[ahead of print]

2. Ansaldo AM, Montecucco F, Sahebkar A, Dallegri F, Carbone F. Epicardial adipose tissue and cardiovascular diseases. Int J Cardiol. 2019 Mar $1 ; 278: 254-60$.
3. Gaeta M, Bandera F, Tassinari F, Capasso L, Cargnelutti M, Pelissero G, et al. Is epicardial fat depot associated with atrial fibrillation? A systematic review and meta-analysis. Europace. 2017 01;19(5):747-52. 